\title{
Microstructure and Wear Behavior of TiC Coating Deposited on Spheroidized Graphite Cast Iron Using Laser Surfacing
}

\author{
Essam R. I. Mahmoud \\ Welding and NDT Lab., Department of Manufacturing \\ Technology, Central Metallurgical Research \& \\ Development Institute (CMRDI), Cairo, Egypt \\ essamibrahim2@yahoo.com
}

\author{
Hashem F. El-Labban \\ Department of Production Engineering, Alexandria \\ University, \\ Alexandria, Egypt \\ drlabbanh@yahoo.com
}

\begin{abstract}
Spheroidal graphite cast iron was laser cladded with TiC powder using a YAG fiber laser at powers of 700, 1000, 1500 and $2000 \mathrm{~W}$. The powder was preplaced on the surface of the specimens with $0.5 \mathrm{~mm}$ thickness. Sound cladding and fusion zones were observed at 700, 1000 and $1500 \mathrm{~W}$ powers. However, at $2000 \mathrm{~W}$, cracking was observed in the fusion zone. At $700 \mathrm{~W}$, a build-up zone consisted of fine TiC dendrites inside a matrix composed of martensite, cementite (Fe3C), and some blocks of retained austenite was observed. In this zone, all graphite nodules were totally melted. In the fusion zone, some undissolved and partially dissolved graphite nodules appeared in a matrix containing bainite, ferrite, martensite and retained austenite. At $1500 \mathrm{~W}$, the fusion zone had more iron carbides and ferrite, and the HAZ consisted of martensitic structure. At $2000 \mathrm{~W}$, the buildup zone was consisted of $\mathrm{TiC}$ particles precipitated in a matrix of eutectic carbides, martensite plus an inter-lamellar retained austenite. The hardness of the cladded area was remarkably improved (1330 HV in case of $700 \mathrm{~W}: 5.5$ times of the hardness of substrate).
\end{abstract}

Keywords- spheroidal graphite cast iron; laser cladding; TiC particles; YAG fiber laser; wear resistance

\section{INTRODUCTION}

Spheroidal graphite cast iron has an excellent castability, good machinability, adequate wear resistance, high strength-toweight ratio, good combination of strength and toughness and high fatigue endurance [1-3]. Such desirable properties widen its applications in machine, automobile, and mining industries. Some applications include machine tool beds, rolling mill rolls, pistons, cylinders, sea water pump housings, and parts of earth moving equipment [4-5]. However, under severe service conditions, its performance and reliability can be limited by various forms of wear, which affect the life of a component and reduce its performance. Improving the surface properties of ductile irons can help coping with these problems [4, 6]. Many different traditional surface modifications such as surface hardening [7] and surface cladding [8,9] are applied to improve the wear and erosion characteristics of ductile irons' surfaces. Various techniques such as thermal spraying [10], plasma spraying [11], traditional arc welding [8,9] and focused energy technologies like electron beam [12] and laser [2, 4-5], have also been employed. The metallurgical bonding between the thermal spraying layers and the substrate is relatively weak, which causes the sprayed material to peel off under high bending stress or heavy loads [13]. The excessive energy input from the traditional welding processes such as shielded metal arc welding or even gas tungsten arc welding may cause some undesirable distortion and residual thermal stresses which may cause cracks in the hardened layer [8-9]. Laser surfacing has been suggested as a potential technique to produce a hard surface layer of ductile irons for a number of reasons. The most important one arises from the fact that this technique provides rapid heating and cooling, which can easily produce special types of microstructures with novel properties that cannot be produced by other conventional processing techniques $[14,15]$. Generally, the obtained microstructure in the laser treated area depends on the heating and cooling cycles that take place during the process, which in turn depends on the laser parameters [16]. Other merits of the laser surfacing are to produce a hard layer with low dilution and deformation, relative cleanliness, lack of quenching medium and limited grain growth during heating [2].

Laser cladding is considered one of the laser surfacing techniques that can produce ductile iron-based-composites clad layers, where hard particles such as carbides, borides, and nitrides are used to reinforce the ductile iron [17]. In this case, the wear properties can be improved by the combination of embedded hard carbide particles and the rapid heating and cooling which forms hard structure matrix. The widely used carbide particles reinforcement is $\mathrm{TiC}$. It has low density, excellent mechanical properties, especially at high temperatures, good thermal stability and high wear resistance [18]. TiC powder has been used previously on a variety of substrates. Liu et al. [19] clad TiC powder on the normal carbon steel substrate; Jiang and Kovacevic [20] clad TiC powder on the tool steel alloy substrate; $\mathrm{Gu}$ et al. [21] clad TiC powder on the Al alloy substrate; and Ravnikar et al. [22] clad $\mathrm{TiC}$ powder on the $\mathrm{Ti}$ alloy substrate. This indicates that the 
wear resistance of the substrate can be improved significantly by cladding TiC powder. Thus, in the present study, we aim to investigate the effects of main laser parameters and rapid solidification on the microstructure, hardness and wear behavior of spheroidal graphite cast iron surface cladded by TiC powder. Microstructural changes in the build-up melted and heat affected zones are examined in details.

\section{EXPRIMENTAL WORK}

Spheroidal graphite cast iron samples, with dimensions of $100 \mathrm{~mm} \times 50 \mathrm{~mm} \times 6 \mathrm{~mm}$ were used as substrate, with chemical compositions listed in Table I. TiC powder with purity of $99 \%$ and particle size of 3-10 $\mu \mathrm{m}$, as shown in Figure 1, was used as reinforcement.

Laser surface cladding using a $3 \mathrm{~kW}$ YAG fiber (Nd:YAG) laser with a defocusing distance of $24 \mathrm{~mm}$ was employed for processing the samples. Before laser treatment, the sample surfaces were mechanically ground and cleaned to remove any contaminates. The TiC powder was preplaced on the surface to form a $0.5 \mathrm{~mm}$ thick film. The experiments were carried out at a fixed traveling speed of $4 \mathrm{~mm} / \mathrm{s}$ and different laser processing powers of $700,1000,1500$ and $2000 \mathrm{~W}$. To produce oxide-free coatings in all experiments, argon shielding gas was used during and after laser cladding at a gas flow rate of $15 \mathrm{~L} / \mathrm{min}$. The transverse cross sections of the deposited beads were cut for microstructural examination. The depths and width of laser treated beads were measured on the cross-sections of treated samples under the given range of processing conditions.

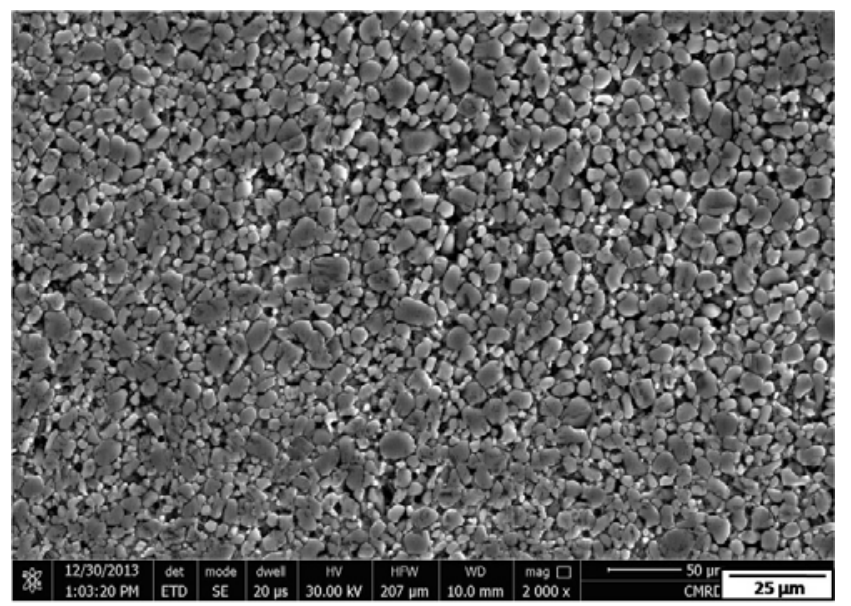

Fig. 1. SEM micrograph of the TiC powder.

The microstructures of the coated layer and substrates were investigated using an optical microscope, a scanning electron microscope equipped with an EDX analyzer and standard methods of metallography. The substrate and the laser treated area were analyzed by X-ray diffractometer (XRD) to identify experimentally the existent phases that were originally found or in situ formed during laser processing. The micro-Vickers hardness in the coated layer cross-section and the substrate were measured with an indentation load of $9.8 \mathrm{~N}$ and loading time of $15 \mathrm{~s}$ at room temperature. The wear behavior of the laser cladded zone was evaluated using a pin-on-disk dry sliding wear tester in air at room temperatures. A stationary sample with a diameter of $2.5 \mathrm{~mm}$ was slid against a rotating disk with a rotational speed of $265 \mathrm{rpm}$ for 15 minutes. The tests were carried out at a fixed load of 1 bar applied to the pin. Before the test, all the specimens were ground using emery paper up to \#600 to get smooth and flattened surface. The specimens were weighted before and after the test with a sensitive electronic balance with an accuracy of $0.001 \mathrm{~g}$. The differences in average mass loss before and after the wear test were measured and accounted. Three specimens of each laser power were chosen for wear tests. The untreated cast iron base metal was selected as the reference material for the wear test.

TABLE I. CHEMICAL COMPOSITION OF THE SPHEROIDAL GRAPHITE CAST IRON SUBSTRATE, WT.\%.

\begin{tabular}{|c|c|c|c|c|c|}
\hline $\mathbf{C}$ & $\mathbf{S i}$ & $\mathbf{M n}$ & $\mathbf{P}$ & $\mathbf{S}$ & $\mathbf{C r}$ \\
\hline 3.82 & 2.7 & 0.237 & 0.02 & 0.014 & 0.03 \\
\hline $\mathbf{N i}$ & $\mathbf{M g}$ & $\mathbf{A l}$ & $\mathbf{V}$ & $\mathbf{C u}$ & $\mathbf{F e}$ \\
\hline 0.03 & 0.05 & 0.02 & 0.007 & 0.02 & Bal. \\
\hline
\end{tabular}

\section{RESULTS AND DISCUSSION}

\section{A. Macro/microstructure analysis}

The basic microstructure of the substrate, as shown in Figure 2, consists of typical spheroidized graphite, surrounded by a narrow crescent of ferrite phase, embedded in a pearlite matrix. This microstructure was confirmed by the XRD analysis shown in Figure 3. In this XRD peaks, alpha phase was the dominant phase together with cementite, which represents the constituents of pearlite, and graphite.
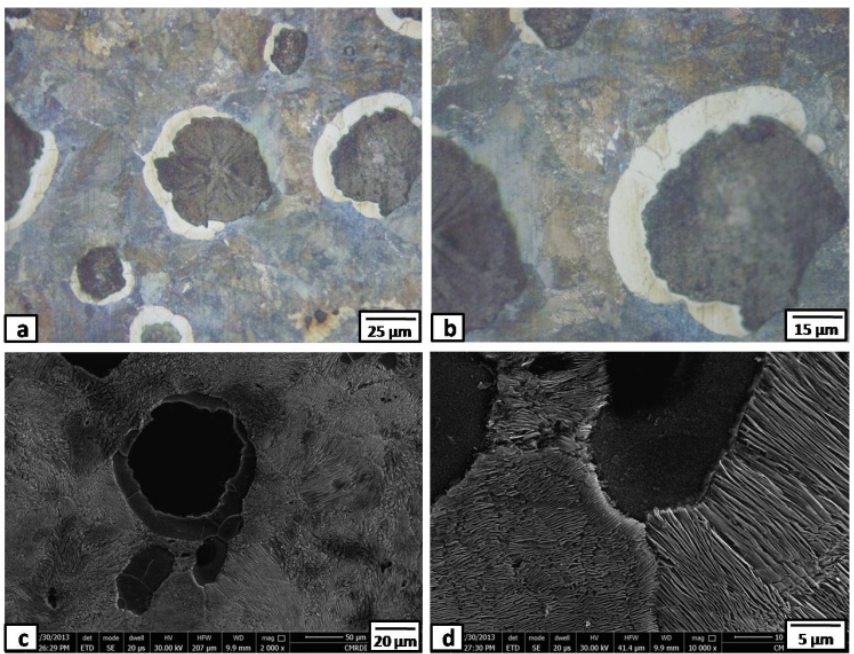

Fig. 2. Optical micrographs (a) and (b), and SEM images (c) and (d) for microstructure of the base metal.

Macro-views of the cross-sections of the surface laser treated layer at different laser powers of 700, 1000, 1500, and $2000 \mathrm{~W}$ are illustrated in the macrographs shown in Figure 4. From these figures, four distinctive zones were observed. These regions are: (i) the build-up zone which refers to the areas enriched in TiC particles and completely melted by laser heating and then solidified, (ii) the fusion zone which appeared 
as a narrow band around the $\mathrm{TiC}$ rich zone in which the substrate material is melted and then solidified, (iii) the heataffected zone (HAZ) which is just beyond the fused zone, which experiences an elevated temperature, but does not melt, and (iv) the substrate, whose microstructure remains unaffected during the laser treatment. The depth and width of the treated layers at different laser powers are shown in Table II. The depth of the treated layer is in direct proportion to the laser power. On the other hand, the laser power has no great effect on the treated zone width.

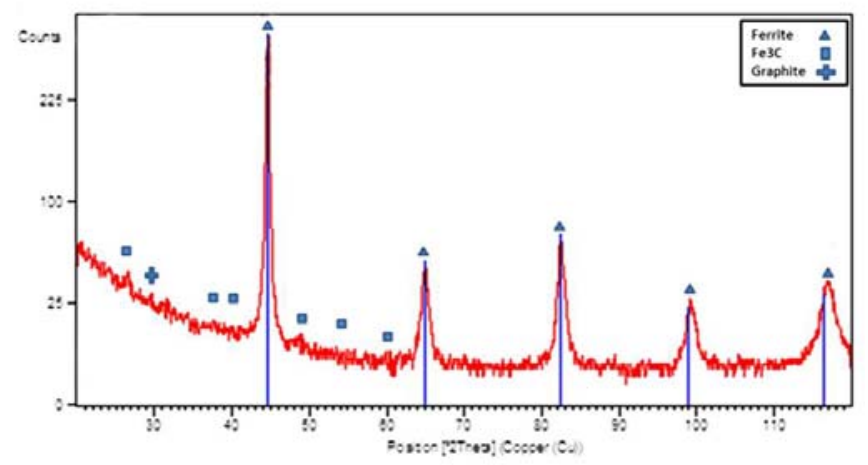

Fig. 3. XRD of the base metal.
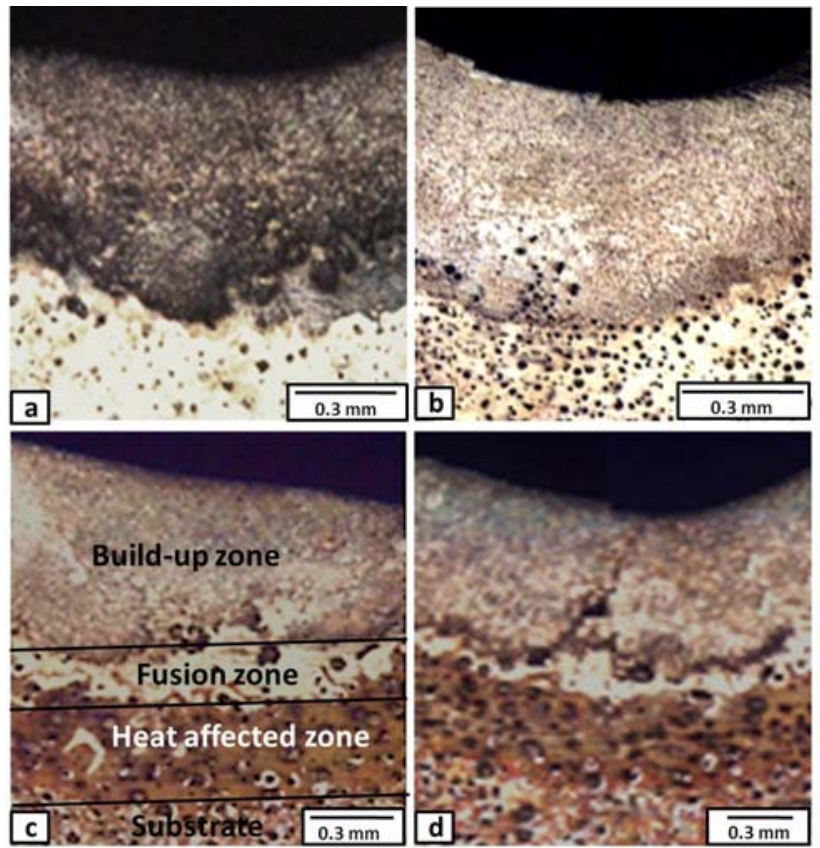

Fig. 4. Optical macrographs of the laser-treated zone cross-sections at different laser processing powers of: (a) $700 \mathrm{~W}$, (b) $1000 \mathrm{~W}$, (c) $1500 \mathrm{~W}$, and (d) $2000 \mathrm{~W}$.

The microstructures of the build-up zone of the sample treated by a laser power of $700 \mathrm{~W}$ are shown in Figure 5. In contrast to the microstructure of the substrate, the laser treated build-up zone was consisted of precipitated particles appeared as a dendritic morphology inside a fine matrix composed of martensite, cementite $\left(\mathrm{Fe}_{3} \mathrm{C}\right)$ and some blocks of retained austenite. Generally, all the constituents have fine microstructure due to the extremely high cooling rate after laser treatment. The EDX analysis of the precipitated dendrites shows that they are $\mathrm{TiC}$, as shown in Figure 6. This means that the $\mathrm{TiC}$ particles are melted and then re-solidified during the laser processing.

TABLE II. DIMENSIONS OF THE LASER BUILD-UP ZONE AT DIFFERENT LASER POWERS.

\begin{tabular}{|c|c|c|}
\hline Laser power, $\mathbf{W}$ & Width, mm & Depth, $\mathbf{~ m m}$ \\
\hline 700 & 0.51 & 1.21 \\
\hline 1000 & 0.52 & 1.29 \\
\hline 1500 & 0.54 & 1.45 \\
\hline 2000 & 0.55 & 1.52 \\
\hline
\end{tabular}

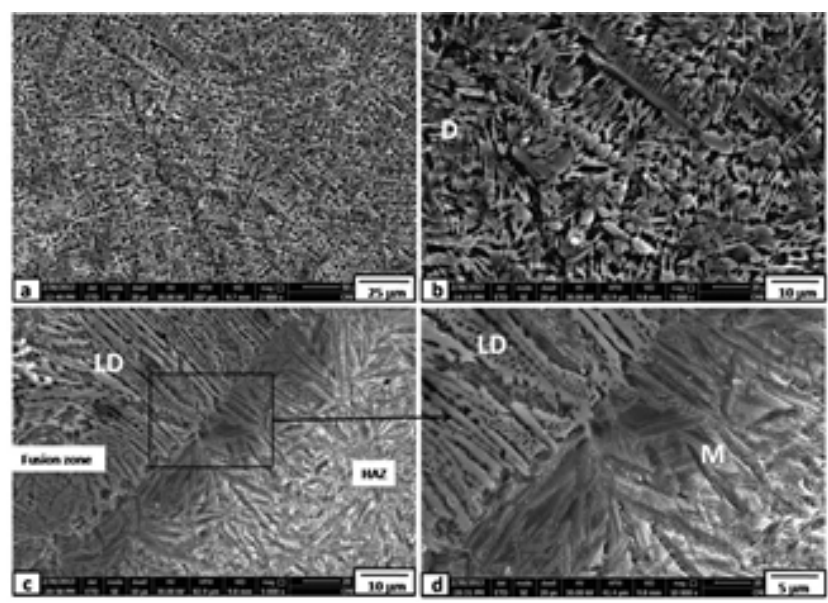

Fig. 5. SEM micrographs of the laser treated areas by processing power of $700 \mathrm{~W}$ where: (a) \& (b) build-up zone, (c) the interface between the fusion zone and heat affected zone (HAZ), and (d) enlarged zone in (c). (M: martensite; D: carbides; LD: ledeburite).

As it is well known, laser technology is characterized by a high energy density and ceramics have a much higher capability to absorb laser energy than metals. [23]. Therefore, TiC particles were melted (or partially melted) in spite of their extremely high melting point. $\mathrm{TiC}$ solidified in a dendritic morphology due to high solidification rates after laser processing, and these results agree well with previously published results [24-26]. It is obviously to note here that all the graphite nodules are totally melted and are no longer formed again during re-solidification. By going down to the fusion zone, as shown in Figures 5(c) and 5(d), the TiC particles/dendrites have disappeared. Its microstructure reveals a martensitic microstructure plus an interlamellar austenite between lathes of cementite, which is called ledeburite. At the bottom of the fusion zone, as shown in Figure 7, some undissolved and partially dissolved graphite nodules appeared in a matrix containing bainite, ferrite, martensite and retained austenite. In this region, complete melting was not achieved but solid-state transformations are occurred. On the other hand, the heat affected zone shows a martensitic structure as shown in the lower part of Figures 5(c), 5(d) and 7. Moreover, the results show that there was no noticeable cracks in the interface of the laser treated zone which appeared to have good 
adherence to the substrate. This interface appeared to have irregular shape, as shown in Figures 4 and 7. This may be due to the extra carbon that came from the dissolution of graphite nodules into their adjacent areas, which lower the local melting point of these areas. Melting occurs first in those carbon enriched areas, and then in the other areas [27].

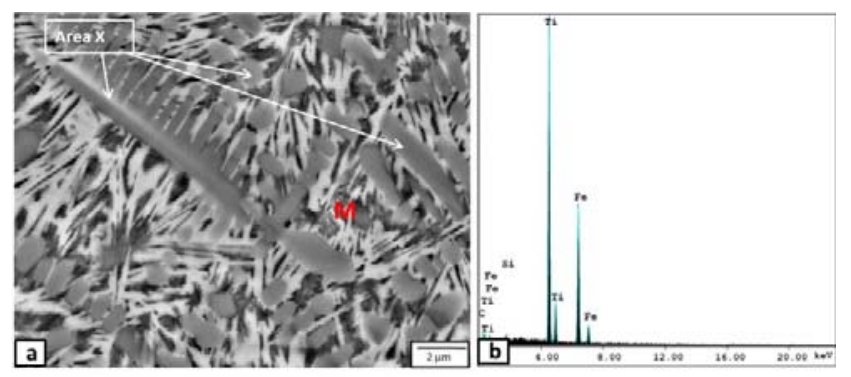

Fig. 6. EDS spectra (b) of the area $\mathrm{X}$ in the enlarged SEM micrograph (a) of the build-up zone in the laser treated zone by processing power of $700 \mathrm{~W}$. (M: martensite)

Figure 8 shows the XRD patterns of the laser treated area at a processing power of $700 \mathrm{~W}$. The laser treated zone showed peaks of titanium carbide, martensite, cementite and retained austenite in different ratios in addition to some traces of ferrite. The rapid cooling after laser treatment forces the nucleation during solidification to occur to temperatures below the liquidus temperature (undercooling) [3]. For this reason, grain refinement and more meta-stable phases can be achieved. On the other hand, carbon diffuses from higher concentration areas to lower concentration areas, where it forms in one hand large amounts of iron carbide (cementite) and in the other hand, leaving behind a low carbon area of ferrite.

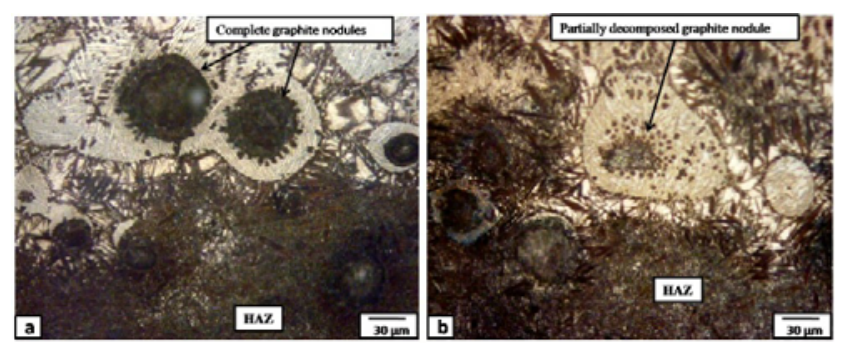

Fig. 7. Optical micrographs of the interface between fusion zone and heat affected zone at laser power of $700 \mathrm{~W}$.

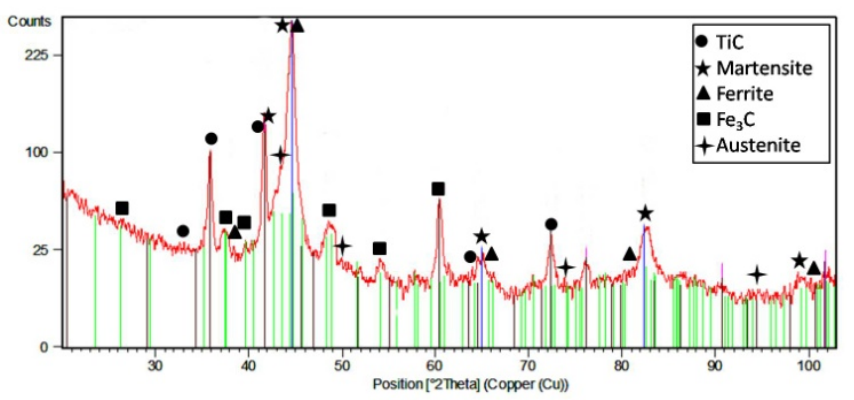

Fig. 8. XRD of the laser treated zone at processing power of $700 \mathrm{~W}$.
By increasing the laser power to $1500 \mathrm{~W}$, the fusion zone resulted in iron carbides $\left(\mathrm{Fe}_{3} \mathrm{C}\right)$ and ferrite, in addition to martensite (Figure 9). This result can be attributed to the decrease of the cooling rate with increasing laser power. This relatively slow cooling rate gave the chance to the carbon of the dissolved graphite to diffuse into a higher concentration area, forming local batches of iron carbides. Ferrite grains were more pronounced around these batches. Martensite plates were also observed in these areas. Moreover, some pores were found at the interface between the melted zone and the heat affected zone (Figure 9(a)). During the laser treatment, combustion of graphite nodules can occur and consequently the graphite can be removed by the shielding gas [5]. The heat affected zone of the sample treated under this condition $(1500 \mathrm{~W})$ is composed of martensite structure (Figure 9(b)).

At a laser power of $2000 \mathrm{~W}$, the build-up zone consisted of $\mathrm{TiC}$ particles precipitated in a matrix of eutectic carbides, martensite plus an inter-lamellar retained austenite (Figures 10(a) and 10(b)). The fusion zone appeared as a wide area and its structure, (Figures 10(c) and 10(d)), was consisted of martensite-transformed primary dendrites, plate-like eutectic carbides, and some ledeburite between the interdendritic structures. This fusion zone structure is very similar to that of white cast iron. Some transverse cracks were detected in the fusion zone (Figure 10(c)). This may be attributed to the coarse carbides which solidified directly from the liquid and formed a continuous brittle network inside the fused area. Moreover, the thermal stresses generated from this higher laser power (2000 W) can contribute to the formation of cracks in this condition.
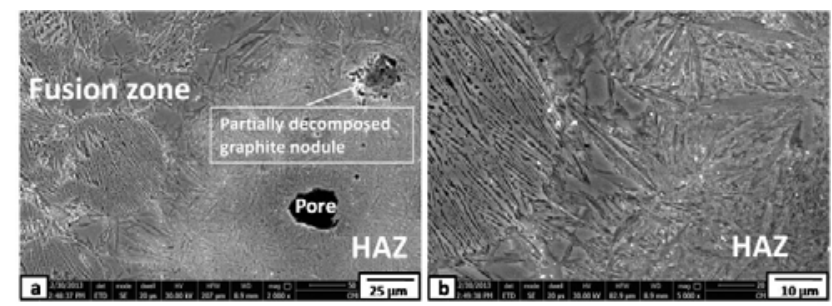

Fig. 9. SEM micrographs of the laser treated zone by processing power of $1500 \mathrm{~W}$
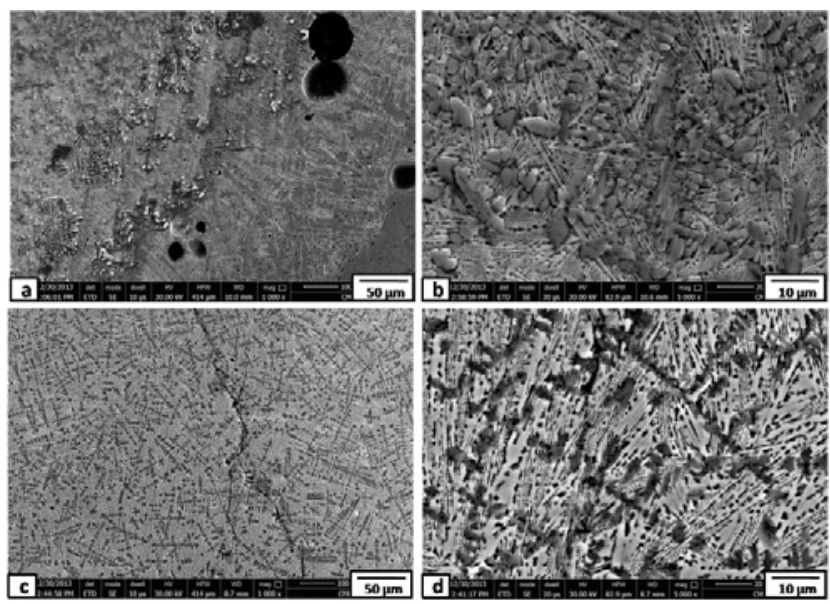

Fig. 10. SEM micrographs of the laser treated zone produced by $2000 \mathrm{~W}$ where: (a) and (b) build-up zone, and (c) and (d) fusion zone. 


\section{B. Hardness measurements}

The microhardness of the base metal was about $240 \mathrm{HV}$. Figure 11 shows the microhardness profiles through the depth of the laser treated zone obtained at different laser powers. The hardness along the depth of the treated zone is found to vary with the distance from the free surface. As the distance from the free surface increases, the hardness decreases. This decreasing of the hardness along the distance may be attributed to the microstructural changes along the depth of the treated layer. It can be seen that the free surface have much higher hardness than that of the substrate, which is related to the combined effect of the added $\mathrm{TiC}$ particles and the formation of hard phases during the re-solidification after the laser surface treatment. The average hardness value at the surface treated with $700 \mathrm{~W}$ and $2000 \mathrm{~W}$ was about $1330 \mathrm{HV}$ and $1100 \mathrm{HV}$, respectively. Decreasing laser power was found to increase the hardness of the treated-zone, which may be attributed to an increased cooling rate.

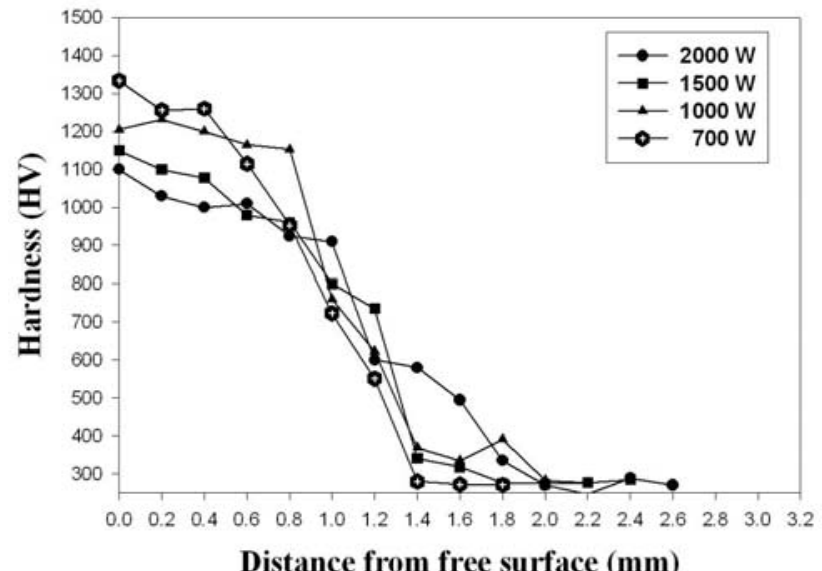

Fig. 11. Microhardness profiles through the depth of the laser treated zone obtained at different laser powers.

\section{Wear resistance}

Figure 12 shows the variation of wear weight loss of the laser cladded cast iron using different powers together with the base metal, after subjected to pin-on-disk dry sliding wear test at a fixed load of 1 bar in air at room temperature. Compared with the cast iron base metal, all the investigated laser cladded samples have far better wear properties under the dry-sliding wear test condition. The weight loss of the sample treated by a laser power of $700 \mathrm{~W}$ was almost 1:40 compared to the untreated sample. This exceptional wear resistance improvement came from the hard, stable, wear resistant TiC dendritic particles which were formed in-situ and were homogenously distributed inside the hard martensite matrix. The experimental results show that the weight losses are increased when increasing the laser power. The relatively faster cooling rate under the lower laser power resulted in refinement of both the reinforcement (TiC particles) and the matrix (full martensite microstructure), which helped to improve the wear characteristics. On the other hand, the relatively slower cooling rate under the higher laser power resulted in relatively course
TiC particles inside a matrix of large martensite lathes and retained austenite.

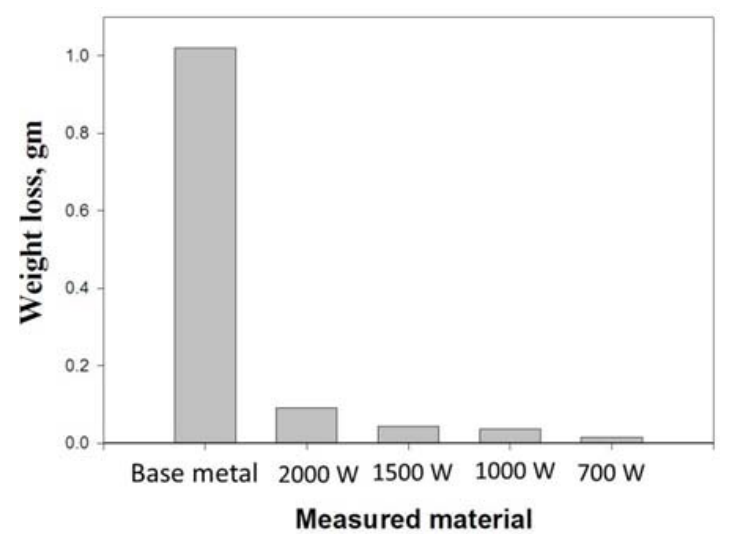

Fig. 12. Wear weight loss of untreated and laser cladded specimens with different laser powers.

\section{CONCLUSION}

Spheroidal graphite cast iron was laser cladded with $\mathrm{TiC}$ powder of $99 \%$ purity and particle size of $3-10 \mu \mathrm{m}$. The powder was preplaced on the surface of the specimens with 0.5 $\mathrm{mm}$ thickness. Laser surface cladding was carried out using a 3 $\mathrm{kW}$ YAG fiber laser at 700, 1000, 1500 and $2000 \mathrm{~W}$ processing powers and fixed traveling speed of $4 \mathrm{~mm} / \mathrm{s}$. To prevent the oxidation, argon gas was used as a shielding gas. The results lead to the following conclusions:

1. The treatment resulted in three zones: Build-up (cladding), fusion, and the heat affected zone (HAZ). The depth of the treated layer is in direct proportion to the laser power. Sound cladded layers were formed when applying 700 , 1000 and $1500 \mathrm{~W}$ processing powers. The treatment under $2000 \mathrm{~W}$ caused cracking in the fusion zone.

2. At $700 \mathrm{~W}$, the laser treated build-up zone microstructure was consisted of fine precipitated $\mathrm{TiC}$ particles appeared with a dendritic morphology inside a fine matrix composed of martensite, cementite $\left(\mathrm{Fe}_{3} \mathrm{C}\right)$, and some blocks of retained austenite. In the cladded zone, all graphite nodules were totally melted and were no longer formed again during the re-solidification. The fusion zone microstructure reveals a martensitic microstructure plus an interlamellar austenite between lathes of cementite.

3. By increasing the laser power to $1500 \mathrm{~W}$, coarse grains and more iron carbides $\left(\mathrm{Fe}_{3} \mathrm{C}\right)$ and ferrite appeared in the fusion zone. The heat affected zone showed a martensite structure.

4. At $2000 \mathrm{~W}$, the build-up zone was consisted of $\mathrm{TiC}$ particles precipitated in a matrix of eutectic carbides, martensite plus an inter-lamellar retained austenite. The fusion zone appeared as a wide area and its structure was consisted of martensite-transformed primary dendrites, plate-like eutectic carbides, and some ledeburite between the interdendritic structures. 
5. The hardness and thus the wear resistance of the cladded layer was remarkably improved due to the combined effect of the added $\mathrm{TiC}$ particles and the formation of hard phases during the re-solidification after the laser surface treatment. The average hardness value at the surface treated by $700 \mathrm{~W}$ was about $1330 \mathrm{HV}$ (5.5 times of the hardness of the substrate). The wear resistance of the sample treated by a laser power of $700 \mathrm{~W}$ was improved almost forty times compared to the untreated sample.

\section{REFERENCES}

[1] M. Shamanian, S. M. R. Mousavi Abarghouie, S. R. Mousavi Pour, "Effects of surface alloying on microstructure and wear behavior of ductile iron”, Materials \& Design, Vol. 31, No. 6, pp. 2760-2766, 2011

[2] G. Sun, R. Zhou, P. Li, A. Feng, Y. Zhang, "Laser surface alloying of CB-W-Cr powders on nodular cast iron rolls", Surface and Coatings Technology, Vol. 205, No. 8-9, pp. 2747-2754, 2011

[3] J. H. Abboud, "Microstructure and erosion characteristic of nodular cast iron surface modified by tungsten inert gas", Materials \& Design, Vol. 35 , pp. 677-684, 2012

[4] B. Podgornik, J. Vizintin, I. Thorbjornsson, B. Johannesson, J. T. Thorgrimsson, M. Martinez Celis, N. Valle, "Improvement of ductile iron wear resistance through local surface reinforcement", Wear, Vol. 274-275, pp. 267-273, 2012

[5] A. Fernandez-Vicente, M. Pellizzari, J. L. Arias, "Feasibility of laser surface treatment of pearlitic and bainitic ductile irons for hot rolls", Journal of Materials Processing Technology, Vol. 212, No. 5, pp. 9891002,2012

[6] X. Qi, S. Zhu, H. Ding, Z. Zhu, Z. Han, "Microstructure and wear behaviors of $\mathrm{WC}-12 \%$ Co coating deposited on ductile iron by electric contact surface strengthening", Applied Surface Science, Vol. 282, pp. 672-679, 2013

[7] K. F. Alabeedi, J.H. Abboud, K. Y. Benyounis, "Microstructure and erosion resistance enhancement of nodular cast iron by laser melting", Wear, Vol. 266, No. 9-10, pp. 925-933, 2009

[8] M. Heydarzadeh Sohi, M. Ebrahimi, H. M. Ghasemi, A. Shahripour, "Microstructural study of surface melted and chromium surface alloyed ductile iron", Applied Surface Science, Vol. 258, No. 19, pp. 73487353, 2012

[9] K. Y. Benyounis, O. M. A. Fakron, J. H. Abboud, A. G. Olabi, M. J. S. Hashmi, "Surface melting of nodular cast iron by Nd-YAG laser and TIG”, Journal of Materials Processing Technology, Vol. 170, No. 1-2, pp. 127-132, 2005

[10] D. Womersley, "Thermal spraying and powder spray welding processes for the hardfacing of grey cast iron", Materials \& Design, Vol. 11, No. 3, pp. 153-155, 1990

[11] Y. Hoshiyama, T. Miyazaki, H. Miyake, "Zirconium carbide dispersed high $\mathrm{Cr}-\mathrm{Ni}$ cast iron produced by plasma spraying", Surface and Coatings Technology, Vol. 228, No. S-1, pp. S7-S10, 2013

[12] R. Zenker, A. Buchwalder, K. Rüthrich, W. Griesbach, K. Nagel, "First results of a new duplex surface treatment for cast iron: Electron beam remelting and plasma nitriding", Surface and Coatings Technology, Vol. 236, pp. 58-62, 2013

[13] P. Fauchais, G. Montavon, "Plasma Spraying: From Plasma Generation to Coating Structure-Review Article", in: Advances in Heat Transfer, Vol. 40, pp. 205-344, 2007

[14] N. Yasavol, A. Abdollah-zadeh, M. Ganjali, S. A. Alidokht, "Microstructure and mechanical behavior of pulsed laser surface melted AISI D2 cold work tool steel”, Applied Surface Science, Vol. 265, pp. 653-662, 2013

[15] B. S. Yilbas, F. Patel, C. Karatas, "Laser controlled melting of HSLA steel surface with presence of $\mathrm{B}_{4} \mathrm{C}$ particles”, Applied Surface Science, Vol. 282, pp. 601-606, 2013

[16] S. P. Gadag, M. N. Srinivasan, B. L. Mordike, "Effect of laser processing parameters on the structure of ductile iron", Materials Science and Engineering: A, Vol. 196, No. 1-2, pp. 145-154, 1995

[17] R. Vilar, "Laser Powder Deposition", in: Comprehensive Materials Processing, Vol. 10, pp. 163-216, 2014

[18] B. Du, S. R. Paital, N. B. Dahotre, "Synthesis of TiB2-TiC/Fe nanocomposite coating by laser surface engineering”, Optics \& Laser Technology, Vol. 45, pp. 647-653, 2013

[19] Y. F. Liu, J. S. Mu, X. Y. Xu, S. Z. Yang "Microstructure and drysliding wear properties of TiC-reinforced composite coating prepared by plasma-transferred arc weld-surfacing process", Materials Science and Engineering A, Vol. 458, No. 1-2, pp. 366-370, 2007

[20] W. H. Jiang, R. Kovacevic, "Laser deposited TiC/H13 tool steel composite coatings and their erosion resistance", Journal of Materials Processing Technology, Vol. 186, No. 1-3, pp. 331-338, 2007

[21] S. T. Gu, G. Z. Chai, H. P. Wu, Y. M. Bao, "Characterization of local mechanical properties of laser-cladding H13-TiC composite coatings using nanoindentation and finite element analysis", Materials \& Design, Vol. 39, pp. 72-80, 2012

[22] D. Ravnikar, N. B. Dahotre, J. Grum, "Laser coating of aluminum alloy EN AW 6082-T651 with TiB2 and TiC: Microstructure and mechanical properties”, Applied Surface Science, Vol. 282, pp. 914-922, 2013

[23] J. Sampedro, I. Pérez, B. Carcel, J. A. Ramos, V. Amigó, "Laser Cladding of TiC for Better Titanium Components", Physics Procedia, Vol. 12-A, pp. 313-322, 2011

[24] A. Chehrghani, M. J. Torkamany, M. J. Hamedi, J. Sabbaghzadeh, "Numerical modeling and experimental investigation of TiC formation on titanium surface pre-coated by graphite under pulsed laser irradiation”, Applied Surface Science, Vol. 258, No. 1, pp. 2068- 2076, 2012

[25] A. Monfared, A. H. Kokabi, S. Asgari, "Microstructural studies and wear assessments of $\mathrm{Ti} / \mathrm{TiC}$ surface composite coatings on commercial pure Ti produced by titanium cored wires and TIG process", Materials Chemistry and Physics, Vol. 137, pp. 959-966, 2013.

[26] R. M. Mahamood, E. T. Akinlabi, M. Shukla, S. Pityana, "Scanning velocity influence on microstructure, microhardness and wear resistance performance of laser deposited Ti6Al4V/TiC composite" Materials and Design, Vol. 50, pp. 656-666, 2013.

[27] H. Yan, A. Wang, Z. Xiong, K. Xu, Z. Huang, "Microstructure and wear resistance of composite layers on a ductile iron with multicarbide by laser surface alloying", Applied Surface Science, Vol. 256, No. 3, pp. 7001-7009, 2010 